\title{
ОБЕСПЕЧЕНИЕ ПРОЗРАЧНОСТИ ФИНАНСОВЫХ ПОТОКОВ В СИСТЕМЕ ГОСУДАРСТВЕННОГО ФИНАНСОВОГО КОНТРОЛЯ
}

\section{MAKING TRANSPARENCY OF FINANCIAL STREAMS IN THE SYSTEM OF STATE FINANCIAL CONTROL}

\section{A. Gavryushenko}

Summary. To study the criteria for financial transparency in the financial control system. Research methods: analysis, synthesis, comparison, generalization, identification of signs, features and properties of phenomena. Research results: the concept of "financial transparency" in general and in the system of financial control is defined, in particular, from the standpoint of international principles, national legislation in the field of financial control and financial and legal doctrine. It is concluded that it is necessary to supplement the criteria for collecting information to ensure the effectiveness of the activities of federal executive bodies (hereinafter - the federal executive authority) with the following criteria: time factor, disclosure of incoming and outgoing information that is not a secret and expansion of controlled entities.

The proposed improvement of the state financial control system in terms of ensuring its transparency for all participants in financial relations will increase the return on the use of budget investments, social efficiency, provide relevant information not only to supervisory authorities, but all interested parties, including potential investors, will increase the level of anti-corruption in the field of procurement.

Keywords: financial monitoring, supervision, financial transparency, financial control.

\section{Введение}

B опросы финансовой прозрачности, долгое время имевшие в большей степени научное значение, были актуализированы резонансными скандалами с Enron и WorldCom[14], а затем мировым финансовым кризисом 2008-2010 годов, который заставил пересмотреть многие финансовые отношения. Именно тот кризис показал, как непрозрачная корпоративная отчетность и слабый государственный финансовый контроль, формировали недостоверную информацию, на основе которой собственники, инвесторы, акционеры, кредиторы, а также государственные органы и служащие, принимали ошибочные решения [15, с.182].

\author{
Гаврюшенко Анна Павловна \\ Аспирант, Российский государственный \\ университет правосудия \\ arork@bk.ru
}

Аннотация. Предметом исследования является изучение понятия и критериев обеспечения финансовой прозрачности в системе финансового контроля. Методы исследования: анализ, синтез, сравнение, обобщение, выделение признаков, особенностей и свойств явлений. Результаты исследования: определено понятие «финансовой прозрачности» в целом и в системе финансового контроля, в частности, с позиций международных принципов, национального законодательства в сфере финансового контроля и финансово-правовой доктрины. Сделан вывод о необходимости дополнения критериев сбора информации для обеспечения эффективности деятельности федеральных органов исполнительной власти (далее - ФОИВ) такими критериями: временной фактор, раскрытие входящей и исходящей информации, не являющей собой тайну и расширение подконтрольных субъектов.

Предложенное совершенствование системы государственного финансового контроля в части обеспечения её прозрачности для всех участников финансовых отношений, повысит отдачу от использования бюджетных вложений, социальную эффективность, обеспечит релевантной информацией не только надзорные органы, а все заинтересованные стороны, включая потенциальных инвесторов, повысит уровень противодействия коррупции в сфере прокьюремента.

Ключевые слова: финансовый мониторинг, надзор, финансовая прозрачность, финансовый контроль.

Широко используемое в нормативном регулировании и доктринальном анализе понятие «финансовая прозрачность» ни там, ни там четко не определяется. Применительно к финансовому контролю оно, как правило, не рассматривается и не определяется его критерии не выявлены, так как эта сфера, относясь к надзорно-конорольным функциями государства, традиционно всегда считалась закрытой. Цель настоящего исследования - ликвидировать указанный пробел.

\section{Метолы и материалы}

Положения и выводы статьи получены с применением системного и формально-логического подходов 
к анализу международных и российских институтов и практик финансового контроля, обеспечения их открытости (прозрачности).

\section{Результаты и их обсужление}

Формально прозрачность финансовых институтов с 2004 г. закреплена в рамках «Международной конвергенции измерения капитала и стандартов капитала: новые подходы» (далее - Базель II) [16], а также - в национальном законодательстве. Так, концептуальные подходы к пониманию финансовой прозрачности заложены в ст. 36 Бюджетного Кодекса РФ, раскрывающей соответствующий принцип, который также обозначен и как принцип открытости. Это опубликование сведений в средствах массовой информации, их обязательная открытость для общества; включая процедуры рассмотрения и принятия решений, обеспечение виртуального доступа к информации, а также стабильность и (или) преемственности действующих классификаций, сопоставимости показателей. Эти принципы представляются универсальными и применимыми к финансовому контролю. В то же время, на практике прозрачность именно в финансовом секторе, «каким бы образом она ни измерялась» признается экспертами «далекой от совершенства» $[17$, с.40].

Во многом дело в том, что до последнего времени считалось, что требование финансовой прозрачности применимо, прежде всего, к субъектам финансового рынка: банкам, страховым компаниям, а также к корпорациям. Российские авторы традиционно исходили из того, что финансовый контроль должен обеспечить финансовую прозрачность подконтрольных субъектов, бюджетных отношений $[18$, с.71] и т.Д., но при этом о собственной прозрачности, речи, как правило, не шло. То, что прозрачной должна стать и противоположная сторона - государственный финансовый контроль, было «открыто» относительно недавно.

В 2019 г. изменения в ст. 265 Бюджетного Кодекса РФ[19], уточнили понимание целей и задач государственного финансового контроля, которые состоят в обеспечении соблюдения положений правовых актов: 1) регулирующих бюджетные правоотношения; 2) обусловливающих публичные нормативные обязательства и обязательства по иным выплатам физическим лицам из бюджетов бюджетной системы РФ; 3) соблюдение условий государственных контрактов, договоров (соглашений) о предоставлении средств из бюджета.

В финансово-правовой доктрине под финансовым контролем принято понимать регламентированную нормами (финансового и административного) права деятельность уполномоченных государственных субъектов по проверке точности и своевременности финансового планирования, полноты и обоснованности поступления доходов в определенные фонды денежных средств, а также эффективности и правильности их использования. Иначе говоря, в узком смысле финансовый контроль следит за законностью формирования, использования и распределения денежных ресурсов [20, с.33].

Финансовый контроль является комплексным финансово-правовым институтом. С позиции современной теории управления его следует считать одним из основных элементов управления. Именно контроль сопоставляет фактические результаты воздействия на управляемый объект с нормативными требованиями и принятыми решениями. При выявлении несоответствий, отклонений и нарушений, контроль инициирует меры по их устранению.

Финансовый контроль может быть как национальным, так и международным. Именно последний, как показывает исторический опыт ${ }^{1}$ и опыт международных проверок Греции и Португалии, формирует правила и приемы обеспечения максимальной прозрачности, но и в свою очередь, может угрожать суверенитету государства.

С позиции системной теории финансовый контроль представляет собой систему институтов: нормативного, организационного обеспечения нормативно заданных правил и форм реализации и контролирующих органов. Как таковая «прозрачность», формально остается факультативным признаком, так как не охватывается нормативным регулированием.

Финансовая прозрачность в её общем понимании означает своевременное и полное (в рамках дозволенного законом) раскрытие информации о производственной, финансовой и иной, связанной с финансами деятельности, равно как и практики управления в этих сферах.

Глобальные и национальные рекомендательные («мягкие») и регулятивные требования, а также общепринятые стандарты финансовой (МФСО - IFRS) и иной отчетности заставляют менеджмент российских компаний и организаций стремиться к максимальной прозрачности, которая в последнее время имеет реальную ценность, репутационную, не только для инвесторов и партнеров, но и практическую, для надзорных и контролирующих органов.

Формально, высокий уровень прозрачности сигнализирует о честности намерений по отношению

Международный финансовый контроль неоднократно устанавливался европейскими государствами (включая Россию) за государственными финансами обанкротившихся Греции в 1856-1857 и 1897 гг.; Туниса (в 1869 г.), Османской империи (в 1875-1881 гг.). 
к контрагентам и государству. Максимальное раскрытие информации, т.е. обеспечение высокой финансовой прозрачности помогает акционерам, инвесторам, аналитикам и проверяющим оценивать текущее состояние и потенциал компании. Также прозрачность остается и внутренней функцией, обеспечивающей, в том числе и внутренний первичный контроль.

Изложенное, классическое понимание финансовой прозрачности лишь отчасти применимо к финансовому контролю, как средству реализации правовой и финансовой политики государства. Его основная задача заключается, прежде всего, в эффективном распределении и использовании государственных средств, разработке финансовой стратегии и тактики. В этом плане государственный финансовый контроль нацелен на: соблюдение всеми его сторонами требований финансового законодательства; анализ финансового состояния государственных организаций; проведение бюджетно-финансового контроля[10].

Реализация курса на модернизацию и инновационное развитие российской экономики в условиях неблагоприятной внешнеполитической и внешнеэкономической конъюнктуры, а также политически мотивированных внешних ограничений (санкций), предъявляет предельно жесткие требования к финансовому контролю, который, по оценке Президента России, призван «добиться действительно прорывных результатов». В данном случае контроль следует рассматривать в виде постоянной обратной связи, при наличии которой формируется "объёмное, объективное видение всей картины», в рамках которой функционирует система изменений. Также контроль, как оценивает Президент России, «к сожалению иногда, так же как и во всём мире, даёт сбои». Задачу финансового контроля Президент России видит в выявлении лучших управленческих решений, пригодных к распространению, равно как и выявления «рисков неэффективности, коррупции, стагнации». В целом, контроль направлен на выявление отдачи, с которой работают вложенные государством ресурсы и оценке оптимальности распоряжения ими[21].

Таким образом, прозрачность финансового контроля в данном случае понимается как открытость, доступность для общества его результатов. Этот подход реализует конституционно значимые цели правового социального государства, действующего в интересах обеспечения прав и законных интересов граждан. Здесь эффективность финансового контроля выступает в качестве одного из основных факторов финансово-экономической устойчивости и социальной стабильности, а также экономической безопасности и благополучия граждан страны [9].
В то же время, такое понимание прозрачности финансового контроля представляется, пусть основным, но все же неполным. Прозрачность в системе финансового контроля, которая очевидно, опосредованно влияет на нормальное функционирование экономики. Исходя из этого контроль должен быть прозрачным не только в плане доступности его результатов для общества, но и аналогично прозрачным для проверяемых. В соответствии с действующим законодательством и по требованию контролирующих органов они обязаны раскрывать финансовую и иную информацию, которая касается коммерческих операций, безопасности, социальной ответственности организации и т.п.[13].

В данном случае все предъявляемые им требования и критерии оценки должны быть заранее известны, открыты и доступны, нормативно закреплены, т.е. прозрачны, а выводы и меры реагирования - иметь возможность для обжалования. Все это в полной мере соответствует общим подходам, закрепленным в «Декларации принципов деятельности контрольно-счетных органов Российской Федерации» [1], где даны основные принципы организации контрольно-счетных органов. Здесь принцип открытости (прозрачности) указан среди принципов плановости, системности, экономичности, независимости и взаимодействия.

Совокупность приведенных принципов также нельзя признать полной. Так прозрачность не может быть абсолютной, а может и отсутствовать, когда контрольные действия связаны с деятельностью и сведениями, составляющими государственную или иную, охраняемую законом тайну.

В соответствии со ст. 265 Бюджетного Кодекса РФ государственный финансовый контроль может быть внешним (осуществляют органы внешнего государственного финансового контроля - Счетная палата РФ, контрольно-счетные органы субъектов РФ); внутренним (осуществляется Федеральным казначейством, органами государственного финансового контроля в структуре органов исполнительной власти субъектов РФ), предварительным (предупреждение и пресечение бюджетных нарушений в процессе исполнения бюджетов) и последующим (осуществляется по результатам исполнения бюджетов для выявления законности их исполнения, достоверности учета и отчетности).

Принцип открытости (прозрачности) в равной степени распространяется на все указанные виды контроля, а соответственно и на деятельность всех указанных органов.

Финансовая прозрачность подразумевает: во-первых, чисто финансовый аспект, т.е. финансовую и бух- 
галтерскую отчетность; во-вторых, допустимую законом прозрачность производственной деятельности, практики корпоративного управления и социальной ответственности, т.е. аспектов с финансами прямо не связанHых.

Принцип прозрачности присущ, в установленных законом, пределах деятельности органов исполнительной власти. Это касается оборота информации об их деятельности, взаимодействии с ФОИВ, органами местного самоуправления, общественными объединениями и гражданами, выработки и реализации государственной политики; нормативно-правового регулирования деятельности и т.д. Финансовая прозрачность в данном случае определяется бюджетным характером отношений.

Прозрачность в деятельности ФОИВ в целом и финансового контроля, в частности, направлена на исключение случаев нарушения прав и законных интересов проверяемых, всех субъектов финансовых отношений, коррупционных рисков, открытости (в установленном законом объеме) данных о доходах, расходах, имуществе и обязательствах имущественного характера сотрудников контроля, совершенствование теории и практики управления институтами контроля, включая соблюдение требований служебного поведения и урегулирование конфликтов интересов, а также - взаимодействие с гражданами и их объединениями.

Органы государственного финансового контроля в целях обеспечения максимальной финансовой про- зрачности могут заимствовать некоторые её критерии у частного и корпоративного сектора, внедряя их в текущую деятельность, добавив к уже существующим критериям. Это может быть, в частности, пока недооцениваемый временной фактор, так как минимизация сроков предоставления и обработки информации повысит скорость доступа к ней в режиме реального времени, а это, в свою очередь, скажется на доверии к системе государственного финансового мониторинга со стороны интересантов и общества. Необходимо отметить, что важно также обеспечить прозрачность входящей и исходящей информации через её раскрытие, (производственная деятельность, практика корпоративного управления, социальная ответственность, положение относительно конкурентов, безопасность) в части, не являющейся тайной.

\section{Зак^ючение}

Таким образом, совершенствование системы государственного финансового контроля позволит повысить конкурентоспособность и инновационные возможности, социальную эффективность и надежность субъектов правоотношений, обеспечить полезной и необходимой информацией все заинтересованные стороны, в том числе зарубежных партнеров и новых потенциальных высококвалифицированных сотрудников, повысить уровень и качество противодействия коррупции через улучшение финансовой прозрачности, которая, в свою очередь, как показывает опыт передовых стран, позволит минимизировать коррупцию и снизить количество финансовых преступлений.

\section{ЛИТЕРАТУРА}

1. Декларация принципов деятельности контрольно-счетных органов российской Федерации. Принята 05.10.2002 IV конференцией Ассоциации контрольно-счетных органов Российской Федерации [Электронный ресурс]: http://www.ksp.mos.ru/ru/docs/dedaration/busmess_principles (дата обращения: 19.12.2019).

2. Постановление Правительства Российской Федерации от 25 августа 2012 г. № 851 «0 порядке раскрытия федеральными органами исполнительной власти информации о подготовке нормативных правовых актов и их общественного обсуждения» (с изменениями и дополнениями) [Электронный ресурс]: http://base.garant.ru/70219366/(дата обращения: 19.12.2019).

3. Указ Президента Российской Федерации от 18.05.2009 № 559 «0 представлении гражданами, претендующими на замещение должностей федеральной государственной службы, и федеральными государственными служащими сведений о доходах, об имуществе и обязательствах имущественного характера» (ред. от 19.09.2017)[Электронный ресурc]: http://www.consultant.ru/document/cons_doc_LAW_87845/(дата обращения: 19.12.2019).

4. Указ Президента Российской Федерации от 13.06.2012 № 808 (ред. от 08.03.2016) «Вопросы Федеральной службы по финансовому мониторингу» [Электронный ресурс]: https://base.garant.ru/70188802/ (дата обращения: 19.12.2019).

5. Федеральный закон от 25 декабря 2008 года № 273-Ф3 «0 противодействии коррупции» [Электронный ресурс]: http://www.consultant.ru/document/cons_ doc_LAW_82959/ (дата обращения: 20.12.2019).

6. Геращенко И.П., Пашкова Т. А. Внешний муниципальный финансовый контроль: теоретический аспект, 2017. - Т. 23, № 43.— С. $2558-2574$.

7. Ермолаев К. С. Финансовый мониторинг как вид финансового контроля [Текст] // Актуальные вопросы экономики и управления: материалы V Междунар. науч. конф. (г. Москва, июнь 2017 г.). — М.: Буки-Веди, 2017. - С. 76-78.

8. Казанкова Т.Н., Трифонова С. А. Проблемы финансового контроля в РФ // Отечественная юриспруденция, 2017. — № 11. — C. 32-33.

9. Сафонова Е. А. Проблемы финансового контроля: практический и теоретический аспекты // Экономика и бизнес: теория и практика, 2017.- Т. 4.4. 2.- C. 90-94. 
10. Шепелев Д. Р. Государственный финансовый контроль в России: проблемы и перспективы [Текст] // Экономическая наука и практика: материалы V Междунар. науч. конференции (г. Чита, апрель 2017 г.).— Чита: Издательство Молодой ученый, 2017.— C. 53-57.

11. Отчет о деятельности Росфинмониторинга [Электронный ресурс]: http://www.fedsfm.ru/content/files/activity/annualreports/otchet_2018\%20 \%D1\%80\%D1\%83\%D1\%81.pdf (дата обращения: 20.12.2019).

12. Федеральная служба по финансовому мониторингу [Электронный ресурс]: http://www.fedsfm.ru/ (дата обращения: 19.12.2019).

13. Финансовая прозрачность. Как ее добиться с помощью BPM и XBRL [Электронный ресурс]: https://iso.ru/ru/press-center/journal/2202.phtml (дата oбращения: 20.12.2019).

14. Dharan, Bala G.; William R. Bufkins Enron: Corporate Fiascos and Their Implications (PDF). Foundation Press, 2004.

15. ДонскаяЛ.А.Финансовый кризис - стимул к повышению прозрачности финансовой отчетности// Актуальные вопросы современной науки. 2009. - № 10.—C. 180-186.

16. Международный комитет по банковскому надзору The Basel Committee. 0фициальный сайт https://www.bis.org/bcbs/index.htm

17. Бацунова С. И. Прозрачность финансовых институтов и рыночная дисциплина Базеля II: на примере Швейцарии// Банковское дело. — 2012.— № 1.— C. $38-42$.

18. Коваленко Е. В. Роль высших органов финансового контроля в усилении прозрачности и открытости бюджетного процесса// Актуальные вопросы современной экономической науки Сб. докладов XVI Международной науч. конф.— М., 2014. — С. 68-74.

19. Изменения внесены федеральным законом от 26.07.2019 № 199-Ф3.

20. Казанкова Т. Н., Трифонова С. А. Проблемы финансового контроля в РФ// Отечественная юриспруденция. — 2017.— № 11.— С. 32-33.

21. Путин В. В. Выступление на XXIII конгрессе Международной организации высших органов финансового контроля (ИНТОСАИ) 25 сентября 2019 г.// http:// www.kremlin.ru/events/president/news/61641

(c) Гаврюшенко Анна Павловна ( arork@bk.ru ).

Журнал «Современная наука: актуальные проблемы теории и практики»

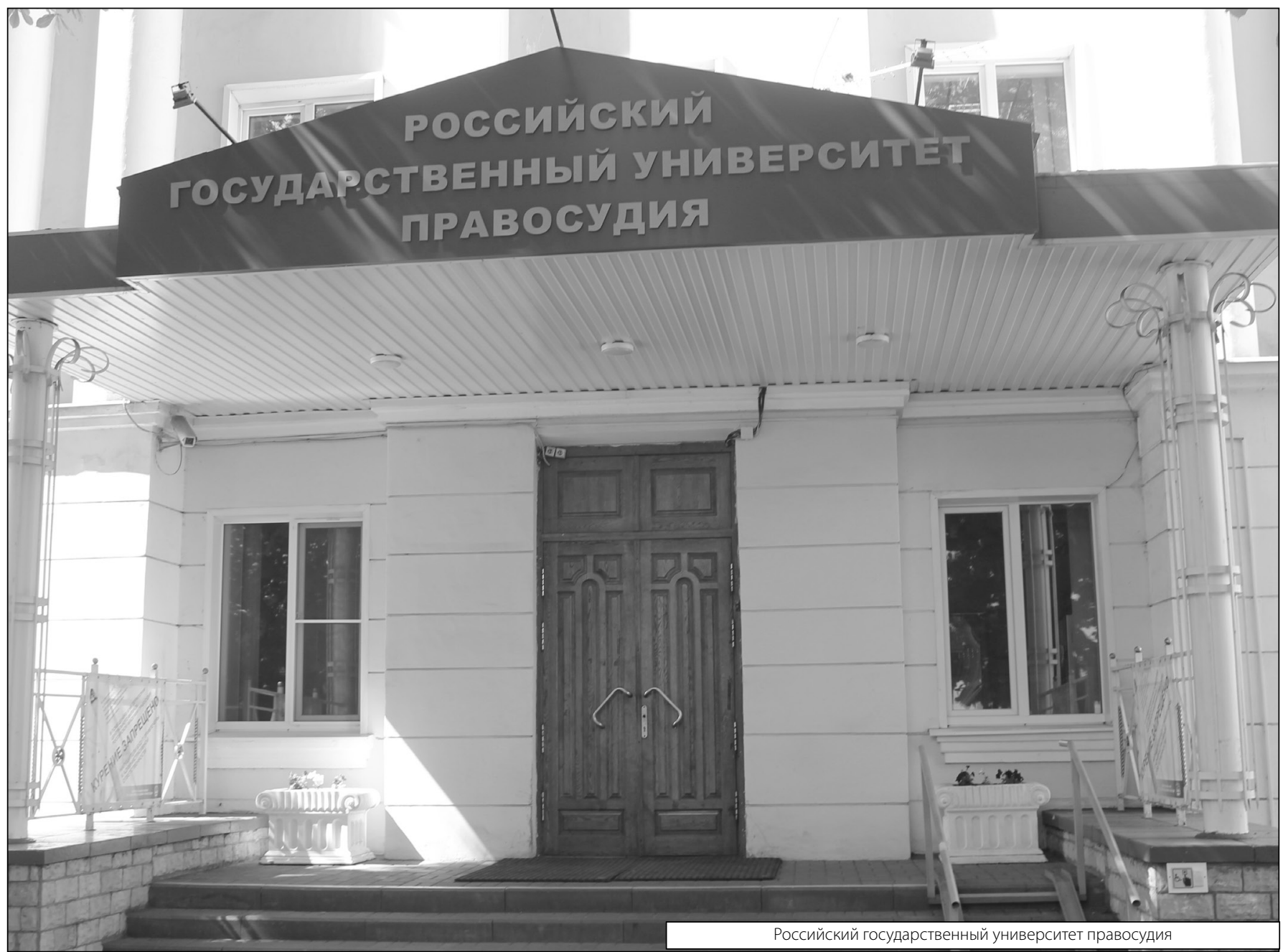

